\title{
Triangular-Shaped Odontoid Process With Chiari 1 Malformation Patient
}

\author{
Katherine Cironi ${ }^{1}$, Joe Iwanaga ${ }^{1}$, Aaron S. Dumont ${ }^{1}$, R. Shane Tubbs ${ }^{1,2,3}$ \\ 1. Department of Neurosurgery, Tulane Center for Clinical Neurosciences, Tulane University School of Medicine, New \\ Orleans, USA 2. Neurosurgery and Ochsner Neuroscience Institute, Ochsner Health System, New Orleans, USA 3. \\ Department of Anatomical Sciences, St. George's University, St. George's, GRD
}

Corresponding author: Joe Iwanaga, iwanagajoeca@gmail.com

\begin{abstract}
Several anatomical variations of osseous structures around the craniovertebral junction (CVI) have been observed in those presenting with Chiari 1 malformation (CM-1) due to the junction's unique embryology and its pivotal role in neck stability. During a clinic visit, a 14-year-old female presented with the classic symptoms of CM-1. Upon follow-up imaging and confirmation of the inferiorly displaced cerebellar tonsils, a unique triangular-shaped odontoid process was identified. To our knowledge, this osseous malformation of the dens has not been reported in the current literature. This unique deviation may cause ligamentous instability and decreased motion capacity and predispose a patient to axial fractures. Thus, we aim to further discuss this case, cervical vertebrae axis (C2) embryology, and the resulting clinical significance of this observed odontoid process variant.
\end{abstract}

Categories: Pediatrics, Neurosurgery, Anatomy

Keywords: odontoid process, morphology, axis, chiari 1 malformation, imaging

\section{Introduction}

Chiari 1 malformation (CM-1) is defined as the caudal displacement of the cerebellar tonsils downward through the foramen magnum, more than $5 \mathrm{~mm}$ below McRae's line [1]. Osseous malformations in the craniocervical junction have been found in about $50 \%$ of patients diagnosed with CM-1 [2]. Due to the unique secondary ossification center in the apical segment of the odontoid process, there is potential for variant architectural growth. Odontoid process angulation has been noted to be associated with increased tonsillar ectopia [3]. Regardless, in normal patients and patients with CM-1, the odontoid process is pegshaped [4]. Here, we present a rare variant of the apical part of the odontoid process in a patient with CM-1. Bringing attention to such an anatomical variation might aid the neurosurgeon, head and neck surgeon, radiologist, pediatrician, and neurologist in diagnosing and understanding unique osseous findings in patients with this type of hindbrain herniation.

Received 08/18/2020 Review began 09/23/2020 Review ended 10/02/2020 Published 10/04/2020

(c) Copyright 2020 Cironi et al. This is an open access article distributed under the terms of the Creative Commons Attribution License CC-BY 4.0., which permits unrestricted use, distribution, and reproduction in any medium, provided the original author and source are credited.

\section{Case Presentation}

A 14-year-old female patient presented to our clinic with a Valsalva-induced headache. Magnetic resonance imaging (MRI) ordered by her pediatrician diagnosed a CM-1. Her headaches occurred three to four times per week and involved the occipital region only. The pain did not radiate beyond the vertex of the skull. Her neurological examination was within normal limits. There was no pain with range of motion of the neck. The CM-1 was found to have 6-7 mm of caudal herniation of the cerebellar tonsils below the foramen magnum. There was no hydrocephalus or syringomyelia. MRI suggested atlanto-occipital fusion. Therefore, computed tomography (CT) of the neck and craniocervical junction was performed, which identified a triangularly shaped odontoid process (Figure 1) and showed herniated cerebellar tonsils (Figure 2). 


\section{Cureus}

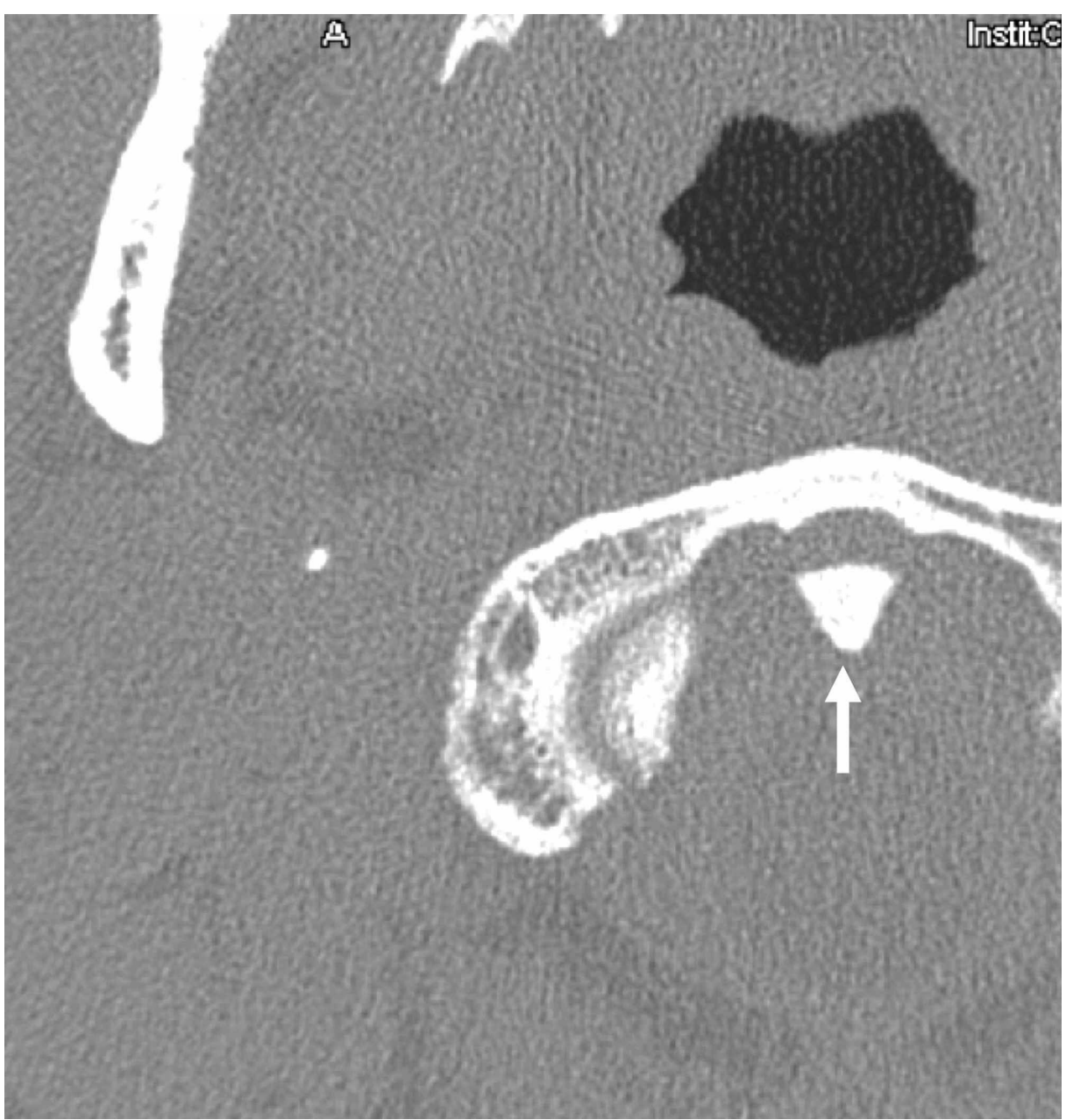

FIGURE 1: Axial CT of the skull in the case

Note the triangular-shaped odontoid process (arrow).

CT: computed tomography

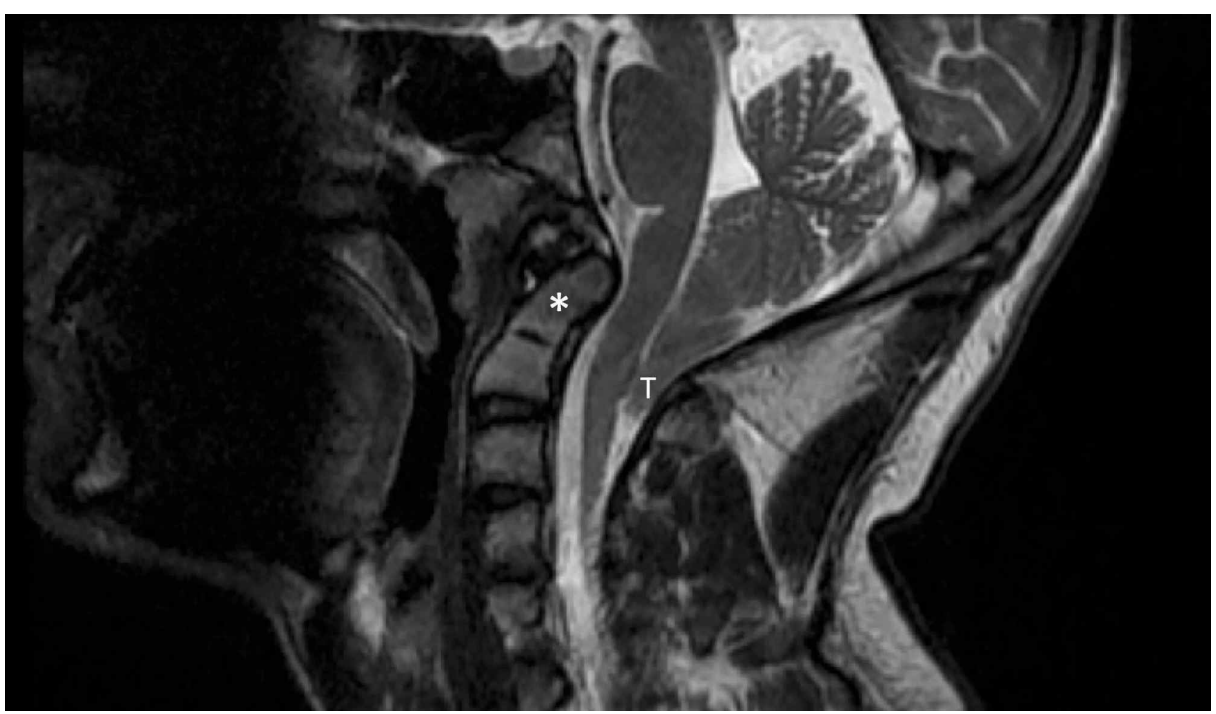

FIGURE 2: T2-weighted, sagittal MRI

Note the herniated cerebellar tonsils (T) indicate a CM-1 and the retroverted odontoid process (asterisk).

MRI: magnetic resonance imaging, CM-1: Chiari 1 malformation 
The length of the process was felt to be within normal limits but the width was shorter than normal at 7.5 $\mathrm{mm}$. No other bony variants, e.g., basilar invagination, were noted, including the suspected atlanto-occipital assimilation. The patient underwent a standard posterior fossa decompression procedure with duraplasty. No complications occurred due to the procedure, and at the one-week follow-up, the wound was healing well and the patient had no complaints of the preoperative Valsalva-induced headache. At the one-year followup, the patient continued to be free of her preoperative symptoms.

\section{Discussion}

Projecting superiorly through the atlas, the odontoid process is of critical importance to the craniovertebral junction (CVJ), with slight variations causing potential instability at the median atlantoaxial joint [5]. Embryologically, the odontoid process is traditionally said to originate from the anterior atlas and then fuses caudally with the body of the axis at the sixth to seventh week of gestation [6-7]. However, these details have been disputed. In general, the odontoid process is formed via two laterally separated primary ossification centers that fuse in the midline by the seventh to eighth month in utero [8]. The midline unified primary ossification center proceeds to grow apart from the body of the axis until its fusion between three and six years of life. This coalescence is termed the subdental synchondrosis $[6,9]$. A cause of the abnormallyshaped odontoid process in our patient may be the growth of the apex being distinct from the odontoid body. This apical secondary ossification center fuses with the remainder of the odontoid process by 12 years of age $[6,9-10]$. The presented case most likely had an abnormal bone growth at the secondary ossification center, causing this anatomical malformation and potentially contributing to CM-1 symptoms, as the triangular-shaped odontoid process protruded further posteriorly than normal.

The variant bone development of the CVI has been well-studied and is commonly seen in patients with CM1. First analyzed by Tubbs et al. [10] and then validated by Ladner et al. [3], some degree of retroflexion of the odontoid process is found in over $80 \%$ of CM-1 patients; furthermore, the odontoid process continues to grow posteriorly with age in this group. This unique growth pattern can cause further compression of the spinal canal, which is already compromised due to the ectopically herniated cerebellar tonsils. The correlation with angulation and increasing tonsillar ectopia should be further studied, as Tubbs et al. [10] found that a posteriorly inclined odontoid process is not correlated with worsening CM-1 symptoms, but higher grades of angulation can be associated with a greater chance of developing syringomyelia. On the contrary, Ladner et al. [3] concluded that more posteriorly displaced cerebellar tonsils were correlated with increasing retroflexion of the odontoid process but no relationship with syringomyelia was noted. Due to the unique structure of this CM-1 patient's odontoid process, the angle of the apex has the potential to further impinge on the downwardly displaced cerebellar tonsils.

The triangular-shaped odontoid process reported here is both thinner and more angled than normal. The mean width of a normal odontoid process is about $11 \mathrm{~mm}[8,10]$, whereas our case's width at its midpoint was only $7.5 \mathrm{~mm}$. The triangular-shaped odontoid process may reduce the stability of the CVJ due to the diminished surface area for its surrounding ligaments to attach. The two alar ligaments have lateral attachments on the odontoid process and insert on the medial aspect of the occipital condyle; between these is the apical ligament, inserting from the apex of the odontoid into the anterior foramen magnum [1112]. Sardi et al. found 16 of the 22 sides to have alar ligaments with posterolateral attachments on the top half of the odontoid process, extending up to the apex [12]. Our misshaped dens may alter the attachment of the alar ligaments and inhibit their main role - to restrict cervical rotation and bending to the contralateral side. Any lesion or tear of these alar ligaments could cause an increased range of motion, potentially leading to occipitocervical instability [12]. Restraining the neck of the odontoid process, the transverse ligament attaches on either side of the transverse ligament tubercles of the atlas. As the strongest of the three, it further constricts the atlantoaxial joint from excessive movement [9]. Karaaslan et al. [13] examined the MRIs of 25 adults with CM-1 and compared those to 93 healthy adult subjects. They found CM- 1 patients have significantly shorter transverse and alar ligaments when compared to the normal population, speculating that ligamentous variations may be a significant cause of disease etiology or progression [13]. Although not substantiated, our variant odontoid process may play a role in further diminished ligamentous stability and motion capacity in the atlas-axial joint in this CM-1 patient. Lastly, a shorter width of the odontoid process might predispose an individual to fractures of the odontoid process [14].

\section{Conclusions}

As variations of the odontoid process can lead to pathology, knowledge of a triangularly shaped process is important. The angulation of the dens noted in this patient with CM-1 may predispose their cerebellar tonsils to further impingement and reduce the stability of the craniocervical junction. This malformation could play a factor in her Valsalva-induced headaches and affect her range of motion in the next few decades of life. Therefore, those clinicians who view imaging of the craniocervical junction should be aware of such varied morphology of the axis.

\section{Additional Information}




\section{Disclosures}

Human subjects: Consent was obtained by all participants in this study. Conflicts of interest: In compliance with the ICMJE uniform disclosure form, all authors declare the following: Payment/services info: All authors have declared that no financial support was received from any organization for the submitted work. Financial relationships: All authors have declared that they have no financial relationships at present or within the previous three years with any organizations that might have an interest in the submitted work. Other relationships: All authors have declared that there are no other relationships or activities that could appear to have influenced the submitted work.

\section{References}

1. Lawrence BJ, Urbizu A, Allen PA, et al.: Cerebellar tonsil ectopia measurement in type I Chiari malformation patients show poor inter-operator reliability. Fluids Barriers CNS. 2018, 15:33. 10.1186/s12987-018-0118-1

2. Fernández AA, Guerrero AI, Martínez MI, et al.: Malformations of the craniocervical junction (Chiari type 1 and syringomyelia: classification, diagnosis and treatment). BMC Musculoskelet Disord. 2009, 10:S1.

3. Ladner TR, Dewan MC, Day MA, Shannon CN, Tomycz L, Tulipan N, Wellons JC: Posterior odontoid process angulation in pediatric Chiari I malformation: an MRI morphometric external validation study. J Neurosurg Pediatr. 2015, 16:171-239. 10.3171/2015.1.PEDS14475

4. Keogh S, Crockard A: Staphylococcal infection of the odontoid peg. Postgrad Med J. 1992, 68:51-54. 10.1136/pgmj.68.795.51

5. Alonso F, Iwanaga J, Chapman JR, Oskouian RJ, Tubbs RS: The corona dentis: description of an anatomic variant with technical implications for anterior odontoid screw placement. World Neurosurg. 2017, 104:132135. 10.1016/J.WNEU.2017.05.029

6. Akobo S, Rizk E, Loukas M, Chapman JR, Oskouian RJ, Tubbs RS: The odontoid process: a comprehensive review of its anatomy, embryology, and variations. Childs Nerv Syst. 2015, 31:2025-2034. 10.1007/s00381015-2866-4

7. Schiller F, Nieda I: Malformation of the odontoid process; report of a case and clinical . Calif Med. 1957, 86:394-398.

8. Montemurro N, Perrini P, Mangini V, Galli M, Papini A: The Y-shaped trabecular bone structure in the odontoid process of the axis: a CT scan study in 54 healthy subjects and biomechanical considerations. J Neurosurg Spine. 2019, 30:585-592. 10.3171/2018.9.SPINE18396

9. Ishak B, Dhaliwal G, Rengifo R, et al.: The retroverted dens: a review of its anatomy, terminology, and clinical significance. World Neurosurg. 2020, 137:304-309. 10.1016/j.wneu.2020.01.231

10. Tubbs RS, Wellons JC, Blount JP, Grabb PA, Oakes WJ: Inclination of the odontoid process in the pediatric Chiari I malformation. J Neurosurg. 2003, 98:43-49. 10.3171/spi.2003.98.1.0043

11. Pérez-Vallina JR, Riaño-Galán I, Cobo-Ruisánchez A, Orejas-Rodriguez-Arango G, López-Muñiz C, Fernández-Martínez JM: Congenital anomaly of craniovertebral junction: atlas-dens fusion with C1 anterior arch cleft. J Spinal Disord Tech. 2002, 15:84-87. 10.1097/00024720-200202000-00018

12. Sardi JP, Iwanaga J, Schmidt C, Rustagi T, Chapman JR, Oskouian RJ, Tubbs RS: Anatomy of the alar ligament: part II: variations of its attachment onto the dens. World Neurosurg. 2017, 107:1007-1011. 10.1016/j.wneu.2017.07.186

13. Karaaslan B, Börcek AÖ, Uçar M, Aykol Ş: Can the etiopathogenesis of Chiari malformation be craniocervical junction stabilization difference? Morphometric analysis of craniocervical junction ligaments. World Neurosurg. 2019, 128:1096-1101. 10.1016/j.wneu.2019.05.072

14. Gebauer M, Lohse C, Barvencik F, Pogoda P, Rueger JM, Püschel K, Amling M: Subdental synchondrosis and anatomy of the axis in aging: a histomorphometric study on 30 autopsy cases. Eur Spine J. 2006, 15:292-298. 10.1007/s00586-005-0990-7 